\title{
VEINTICINCO AÑOS DEL CONSEJO GENERAL DEL PODER JUDICIAL
}

\author{
MANUELTEROL BECERRA \\ Catedrático de Derecho Constitucional \\ Universidad de Huelva
}




\section{SUMARIO}

1. De las polémicas suscitadas en torno al Consejo General del Poder Judicial. 2. De la crítica estructural al Consejo General del Poder JudICIAL. 2.1. La Ley Orgánica del Consejo General del Poder Judicial. 2.2. Sobre "la existencia y aun la probabilidad de ese riesgo". 2.3. El Pacto de Estado para la reforma de la Justicia. 2.4. La Ley Orgánica 2/2001, de 28 de junio. 3. SOBRE LAS CRITICAS COYUNTURALESY LAS DE CARÁCTER PERIÓdico al CONSEJo. 


\title{
VEINTICINCO AÑOS DEL CONSEJO GENERAL DEL PODER JUDICIAL
}

\author{
POR \\ MANUELTEROL BECERRA \\ Catedrático de Derecho Constitucional \\ Universidad de Huelva
}

\section{DE LAS POLÉMICAS SUSCITADAS ENTORNO AL CONSEJO GENERAL DEL PODER JUDICIAL}

Sin duda alguna que el sentimiento más extendido entre los españoles ante su Constitución vigente es el de satisfacción. Por fin parece compartir la sociedad española el convencimiento de necesitarse un orden objetivo y normativo inviolable que aleje a la vida estatal de la arbitrariedad desmesurada e informe, así como la certidumbre de coincidir este orden con el establecido por la Constitución. Con lo que eso significa en cuanto a negarle carácter exclusivamente fáctico. De igual modo parece haber calado en nosotros la idea respecto a que la legitimidad de su origen debe ser permanentemente renova$d a, y$, en relación con esto último, la percepción de requerir este orden un tratamiento distinto al de una ley concebida por el intelecto al margen de la voluntad humana, en el sentido de precisar para adquirir y consumar su vigencia de actos de voluntad ${ }^{1}$.

1 Cfr. HESSE, Konrad, "La fuerza normativa de la Constitución", en Escritos de Derecho Constitucional, Madrid, Centro de Estudios Constitucionales, 1983, pág. 71. 
Desde luego que nada de eso inmuniza a la Constitución de las propuestas tendentes a reformarla, desde el momento en que todo enunciado constitucional encierra una formulación política cuestionable desde ese punto de vista. Dicho sea sin perjuicio de las formulaciones que, en este mismo sentido, pueda inspirar el análisis de cualquier Constitución desde la óptica inherente a la propia lógica del sistema que instaura. Pues, como aquellas críticas políticas a la Constitución, también estos llamamientos a su perfectibilidad concluyen por apelar a la reforma constitucional. Recuérdese a este propósito la insistencia con que la doctrina ha calificado de disfuncional el tratamiento que concede la Constitución al Senado, y ha subrayado al hacerlo la conveniencia de convertirlo en una auténtica Cámara de representación territorial.

Pero, consideraciones de constitutione ferenda al margen, es indiscutible que todos y cada uno de los órganos alumbrados por la Constitución de 1978 han desempeñado fielmente, desde el primer día hasta hoy, el cometido que esta les encomienda. Cuestión distinta es que sus respectivas resoluciones puedan ser cuestionadas, como ha venido sucediendo $y$ es previsible que suceda en el futuro con no pocas decisiones del Consejo, considerando el cúmulo de circunstancias que favorecen la crítica de su quehacer cotidiano. Téngase en cuenta que este tipo de reproches se han verificado en el contexto de una disputa política que se inauguró con la primera regulación legislativa del órgano, alcanzó su mayor intensidad tras la aprobación de la Ley Orgánica del Poder Judicial, y de la que sólo el tiempo dirá si logrará zanjarla la Ley Orgánica $2 / 2001$, de 28 de junio. Se trata del debate relativo a la fórmula más idónea de acometer el desarrollo legislativo de las previsiones constitucionales atinentes a la designación de los vocales judiciales del Consejo. Y no se pase por alto que esta polémica ha discurrido en paralelo con las suscitadas periódicamente con ocasión de cada renovación del órgano.

La sucinta regulación constitucional del Consejo, sin duda que calculada, considerando el grupo de enmiendas orientadas a configurar con cierto detalle la institución que fueron rechazadas durante el debate constituyente, supone casi una invitación a polemizar sobre su diseno legislativo definitivo. Asunto éste tanto más merecedor de atención cuanto ese parco tratamiento que concede al Consejo la Constitución, incluye, sin embargo, una habilitación expresa al legislador orgánico para que defina los perfiles del órgano apenas esbozado en ella.

Recuérdese a este propósito que no son muchas las disposiciones constitucionales dedicadas al Consejo General del Poder Judicial. 
Las cuales se ocupan, en primer lugar, de confiarle el gobierno del Poder Judicial y de encomendar a la Ley Orgánica las definiciones de su estatuto, del régimen de incompatibilidades de sus miembros, así como de sus funciones. En esto es categórico el art. 122.2 de la Constitución, que, a este último propósito, todavía se ocupa de expresar qué tareas debe desempeñar ineludiblemente el Consejo, pues, no en balde, le reclama dicho precepto constitucional a la Ley Orgánica encargada de su desarrollo que incluya entre sus determinaciones la regulación más oportuna "en materia de nombramientos, ascensos, inspección y régimen disciplinarion. En segundo lugar, también demanda la Constitución del Consejo que desempeñe la tarea, descrita en su art. 159.2, relativa al nombramiento de dos de los doce magistrados del Tribunal Constitucional.

En tercer lugar y, por último, destina la Constitución su art. 122.3 a regular la composición del Consejo y el modo de designar a sus miembros, en términos bastante más detallados de los que, según se ha visto, emplea este mismo precepto en su apartado inmediato anterior para definir sus funciones. Excepción hecha del tratamiento que este art. 122.3 dedica a la designación de los miembros del Consejo procedentes de la judicatura, a cuyo propósito no se olvide que el precepto ahora considerado apenas se ocupa de dichos vocales sino para definir su número, doce, y estipular que serán nombrados "entre Jueces y Magistrados de todas las categorías judiciales, en los términos que establezca la ley orgánican. De modo que, como puede observarse, sigue este inciso del art. 122.3 la pauta del art. 122.2, en tanto que adopta el tono escueto, rayano en la parquedad de dicha disposición, al tiempo que reproduce su remisión a la ley orgánica.

Sin embargo, conviene insistir en que las críticas recibidas por el Consejo han sido de muy diversa naturaleza y no siempre las ha inspirado algún extremo de su tratamiento legislativo, tributario del constitucional. Es más, se entiende aquí que admiten clasificarse en los tres grandes grupos mencionados más arriba. Las de índole estructural, pues versan sobre las sucesivas soluciones dadas por el legislador al modo de designar a los vocales judiciales. Las de carácter coyuntural, como son las cosechadas por no pocas de sus decisiones. $Y$ las que periódicamente originan los retrasos de las Cortes Generales a la hora de renovar los mandatos de los consejeros.

Ocasión habrá de ofrecer datos reveladores de cómo en las disputas políticas suscitadas, hasta hace muy poco, acerca del órgano, no era polémico que tales críticas han concluido por desprestigiarlo. Puede que así sea, pero de ahí a sostener que la erosión del Consejo haya 
alcanzado a ser preocupante media un largo trecho que no se recorrerá en estas páginas. ¿Cómo mostrar preocupación al respecto cuando, según revelan los datos aportados por el Centro de Investigaciones Sociológicas, en su encuesta sobre la democracia y sus instituciones de 1999, la última de esta clase publicada al tiempo de redactar estas líneas, sólo el $5 \%$ de los encuestados conoce bien las funciones que le corresponde desempeñar al Consejo General del Poder Judicial y el $34 \%$ únicamente tiene alguna idea al respecto, mientras que el $62 \%$ no conoce cuales son esas funciones, sin contar con el $1 \%$ que no contesta? ${ }^{2}$.

Es más, ni siquiera los jueces parecen estimar que el Consejo esté especialmente desprestigiado, pues no habrían contestado entonces, a finales de 1999, a la pregunta de si el órgano defiende adecuadamente la independencia judicial en los siguientes términos: el 18\% claramente sí, el $36 \%$ más bien sí, el $29 \%$ más bien no, el $16 \%$ claramente no, evitando tan sólo el $1 \%$ no contestar ${ }^{3}$. Como seguramente que tampoco habrían concedido en esa misma encuesta, utilizando una escala de 0 a 10, una puntuación media de 8,5 al grado de independencia de la justicia respecto de los poderes políticos, y de 8,4 al grado de independencia de la justicia respecto de los poderes sociales, valoración que, en ambos casos, está referida al desempeño de las funciones jurisdiccionales ${ }^{4}$.

\section{DE LA CRITICA ESTRUCTURAL AL CONSEJO GENERAL DEL PODER JUDICIAL}

\subsection{La Ley Orgánica del Consejo General del Poder Judicial}

Las críticas más numerosas y de mayor calado en que se ha visto envuelto el Consejo comparten entre sí la característica de contes-

2 Cfr. "Datos de opinión. La democracia y sus instituciones", Boletín 20, abril-junio de 1999. Estudio CIS 2309, diciembre 1998.

En: www.cis.es/boletin/20/democracia.html.

3 Cfr. Quinto Barómetro Interno de Opinión. E62I326 - Diciembre 1999.

4 Cfr. ibidem. Los datos son destacados en el Séptimo Barómetro de Opinión, realizado para el Consejo General del Poder Judicial por Demoscopia, S.A., bajo la dirección de José Juan Toharia. Cfr. Informe CENDOS, Consejo General del Poder Judicial E-62J181, noviembre de 2000, pág. 108. 
tar las diversas soluciones ofrecidas por el legislador al modo de designar a sus vocales judiciales. A cuyo propósito, no está de más recordar que en el debate constituyente se dejaron oír voces de Diputados y Senadores favorables y contrarios a que los Consejeros judiciales fueran elegidos por la judicatura misma. Pues el dato ayuda a interpretar el silencio al respecto del art. 122.3 de la Constitución como una indefinición calculada en la que ambos tipos de solución son posibles. De hecho, el legislador orgánico ha ensayado una fórmula detrás de la otra hasta finalmente combinarlas del modo que contempla la legislación vigente.

No se olvide que la Ley Orgánica 1/1980, de 10 de enero, del Consejo General del Poder Judicial, tras establecer en su art. 8 que los doce vocales de extracción judicial serian elegidos entre jueces y magistrados pertenecientes a todas las categorías judiciales, disponía en el art. 12 que esos mismos vocales serían elegidos por todos los jueces $y$ magistrados en activo.

Desde luego que la Ley Orgánica del Consejo General del Poder Judicial nació con una vocación de transitoriedad marcada por la urgencia de poner en funcionamiento elTribunal Constitucional, y acaso, también, por el propósito razonable de contar con un interlocutor cualificado al que escuchar a la hora de confeccionar la Ley definiti$v^{5}$. Sin embargo, nada hacía presagiar en 1980 que esa provisionalidad terminaría alcanzando al sistema previsto en ella para la propuesta de los vocales judiciales del Consejo, como finalmente sucedió. Téngase presente que a este respecto que, en virtud de la Ley Orgánica 6/1985, de 1 de julio, del Poder Judicial, tales consejeros judiciales serían elegidos mediante la fórmula que contempla la Constitución para designar a los miembros no judiciales del Consejo, de modo que, a la postre, todos los consejeros serían propuestos por el Congreso de los Diputados y el Senado mediando una mayoría favorable al efecto de tres quintos en cada Cámara.

Considérese además que la solución hasta aquí descrita de la Ley Orgánica 6/1985, de 1 de julio, del Poder Judicial, era, según sus mentores, más democrática y politizaba menos el Consejo que cualquier otro tipo de representación corporativa que se instaurase. En concre-

5 Cfr. Sainz de Robles, Federico Carlos, «Poder judicial y Consejo General del Poder Judicial", en la obra colectiva La Constitución Española de 1978. 20 años de democracia, Madrid, Congreso de los Diputados, Centro de Estudios Políticos y Constitucionales, pág. 397. 
to, argumentaban que, de un lado, la mayoría de tres quintos prevista para la elección de todos sus vocales requería inevitablemente de un consenso entre las fuerzas políticas en cada momento presentes en las Cortes, y que, de otro, mitigaba la politización a la que conducia el desarrollo de un proceso electoral entre jueces y magistrados, en el cual, por su propia dinámica, las asociaciones de la judicatura que concurriesen al mismo se verían abocadas a sostener posiciones de naturaleza política, alejadas, por tanto, de la actividad orientada a la defensa de sus intereses profesionales.

En todo caso, obsérvese que el tratamiento concedido por la Ley Orgánica del Poder Judicial al modo de designar a los miembros del Consejo impedía continuar otorgándole la consideración que hasta entonces le habían dispensado ciertos sectores de la judicatura, inclinados a estimarlo como un órgano de representación corporativa de jueces y magistrados, cuya reacción no se hizo esperar. Pues, no en balde, además de los conflictos constitucionales de competencia trabados entre el Consejo General del Poder Judicial y cada una de las Cámaras Legislativas ${ }^{6}$-dirimidos mediante la STC 45/1986, de 17 de abril-, y del recurso de inconstitucionalidad que interpusieron 55 Diputados contra la Ley Orgánica del Poder Judicial - resuelto por la STC 108/1986, de 29 de junio-, la Asociación Profesional de la Magistratura interpuso un recurso de amparo contra los Reales Decretos 1881 y $1882 / 1985$, de 16 de octubre, por los que se nombraban a los vocales del Consejo General del Poder Judicial propuestos con arreglo a lo previsto en el art. 112.3 de la Ley Orgánica del Poder Judicial. Recurso este último en el que los demandantes invocaron el derecho de elección activo y pasivo para cubrir los doce puestos de vocales que, según afirmaban, les correspondia proponer a los jueces y magistrados integrantes del Poder Judicial en su órgano de gobierno, atendiendo a lo dispuesto en el art. 122.3 de la Constitución y a los postulados de su art. 23. Quienes, de acuerdo con todo ello, concluían solicitando que se declarase no sólo la nulidad de los nombramientos, sino también la inconstitucionalidad de la citada Ley. Pretensiones que desestimó el Tribunal Constitucional mediante su Auto 942/1985, de 18 de diciembre.

6 Originados por los acuerdos plenarios del Congreso, de 28 de marzo de 1985; del Senado, de 13 de junio de 1985, y del Congreso, de 20 de junio de 1985, correspondientes a las distintas fases del proceso parlamentario seguido para la aprobación de la Ley Orgánica del Poder Judicial. 


\subsection{Sobre «la existencia y aun la probabilidad de ese riesgo»}

A propósito de las respuestas del Tribunal a esas otras cuestiones que se le plantearon apenas interesa traer a colación su actitud, ciertamente polémica de la STC 108/1986, de 26 de julio, bien que enmarcada en un contexto argumental irreprochable en cuanto a razonabilidad. Conviene no pasar por alto a este último respecto que en dicha resolución ofrecía el Tribunal Constitucional un completo recordatorio sobre el proceso de elaboración del art. 122.3 de la Constitución, que culminaba con una declaración lo bastante interesante como para transcribirla:

"Verdad es que del tono de los debates constitucionales, e incluso de los que tuvieron lugar con motivo de otros proyectos de Ley $y$ de la insistencia en tales debates en que los jueces y magistrados elegibles lo sean "de todas las categorías de la Carrera Judicial", según el texto finalmente aceptado, parece deducirse la existencia de un consenso implícito sobre la necesidad de que los doce vocales procedentes de la Carrera Judicial expresasen no sólo diferentes niveles de experiencia por su función y su edad, sino las distintas corrientes de pensamiento existentes en aquella, pero este consenso no parece extenderse hasta la determinación del procedimiento adecuado para alcanzar tal resultado, de forma que no se constitucionalizó una fórmula concreta, sino que los constituyentes se limitaron a remitirla a una futura ley orgánica» ${ }^{7}$.

Por lo que además se hacía constar en dicha Sentencia no puede decirse que el Tribunal albergara ninguna duda sobre el significado teleológico del precepto, en el que advertía enunciado el propósito de obtener un objetivo dual. De una parte, "asegurar la presencia en el Consejo de las principales actitudes y corrientes de opinión existentes en el conjunto de jueces y magistrados en cuanto tales, es decir, de cuáles sean sus preferencias políticas como ciudadanos". De otra, «equilibrar esta presencia con la de otros juristas que a juicio de ambas Cámaras, puedan expresar la proyección en el mundo del Derecho de otras corrientes de pensamiento existentes en la sociedad". En definitiva, para elTribunal "la finalidad de la norma sería así, cabría afirmar de manera resumida, la de asegurar que la composición del Consejo refleje el pluralismo existente en el seno de la sociedad y muy especialmente en el seno del Poder Judicial” 8 .

7 Cfr. STC 108/1986, de 29 de julia, F.J. 13.

8 Cfr. ibidem. 
Pues bien, aunque a juicio del Tribunal dicha finalidad era fácil de alcanzar atribuyendo a los propios jueces y magistrados la facultad de elegir a doce de los miembros del Consejo General del Poder Judicial, aceptaba asimismo que pudiera conseguirse el objetivo enunciado en el art. 122.3 de la Constitución de emplearse el procedimiento contemplado en el art. 112.3 de la Ley Orgánica del Poder Judicial, consistente en atribuir también a las Cortes la facultad de proponer a los miembros del Consejo procedentes de la judicatura, máxime cuando, según explicaba, la Ley adoptaba la cautela de exigir una mayoría cualificada de tres quintos en cada Cámara ${ }^{9}$.

Pero si las referidas consideraciones delTribunal Constitucional, correspondientes a su STC 108/1986, son irreprochables, no puede decirse otro tanto de las que formulaba a continuación, en tanto que alimentaban, en vez de contribuir a sofocar, la polémica política suscitada, desde la aprobación de la Ley referida, entre partidarios y detractores de configurar al Consejo como un órgano proclive a la defensa de los intereses corporativos de jueces $y$ magistrados. Téngase en cuenta que, según añadía, mediaba el riesgo de frustrarse la finalidad señalada en la Norma Constitucional si, olvidando cuál era el objetivo perseguido por ésta, atendían las Cámaras únicamente a la división de fuerzas existentes en su seno para distribuir los puestos a cubrir entre los distintos partidos, en proporción a su respectiva fuerza parlamentaria ${ }^{10}$. De ahí que concluyese manifestando el Tribunal:

"La existencia y aun la probabilidad de ese riesgo, creado por un precepto que hace posible, aunque no necesaria, una actuación contraria al espíritu de la norma constitucional parece aconsejar su sustitución, ya que es doctrina constante de este Tribunal que la validez de la ley ha de ser preservada cuando su texto no impide una interpretación adecuada a la Constitución. Ocurriendo así en el presente caso, pues el precepto impugnado es susceptible de una interpretación conforme a la Constitución y no impide necesariamente actuaciones contrarias a ella, procede declarar que ese precepto no es contrario a la Constitucións"

No era desde luego habitual en esa época, aunque tampoco fuera del todo desconocido, que el Tribunal efectuase consideraciones de lege ferenda como las vertidas en su manifestación recién des-

\footnotetext{
9 Cfr. ibidem.

10 Cfr. ibidem.

1 Cfr. ibidem.
} 
crita ${ }^{12}$. Mediante la cual, si bien es verdad que sólo llamaba la atención sobre la conveniencia de mantener apartado al Consejo de la vida política, admite interpretarse como un juicio jurisprudencial expresivo de inquietud sobre sí mismo, porque pudieran concederle las Cortes el tratamiento que rechazaba para el Consejo. Al fin y al cabo el sistema adoptado en la Ley Orgánica del Poder Judicial para designar a los vocales del Consejo era idéntico al constitucionalmente previsto para proponer a ocho de los doce magistrados que componen el Tribunal Constitucional. Tal podría haber sido el doble propósito de su incursión en el debate político, bien que con tan poco acierto como escaso éxito.

Si difícilmente cabe calificar de acertadas las referidas consideraciones del Tribunal, es porque aprovechaba la ocasión que el análisis del Consejo le brindaba para, a fin de cuentas, expresar una preocupación en torno a su propia suerte. Identificándose así con un órgano completamente distinto, por ser del todo diferente la naturaleza de sus respectivas funciones. De orden jurisdiccional en el caso del Tribunal Constitucional y precisadas por tanto de la independencia que este propugna en la Sentencia, y de índole político-administrativa en el de la institución que se analiza, requerida tan sólo de la separación respecto del Gobierno que confía conseguir la Constitución configurándolo como un órgano colegiado y plural.Y si tampoco puede decirse que al Tribunal le acompañara la fortuna en su propósito de sustraer al Consejo del terreno político es porque sus palabras sólo podían contribuir a incrementar el tono de la disputa, ya iniciada cuando se dictó la STC 108/1986, sobre el sistema contemplado en la Ley Orgánica del Poder Judicial para la designación de los vocales judiciales del Consejo.

Dicho sea en otros términos, las manifestaciones jurisprudenciales referidas llovían sobre el terreno mojado del debate parlamentario, suscitado durante la tramitación de la Ley Orgánica del Poder Judicial, atinente al mejor modo de designar a los vocales judiciales. Disputa en la que participaron, bien que extramuros de las Cortes, como no podía ser de otra forma, las asociaciones profesionales de la judicatura, privadas del protagonismo que les concedía la Ley Orgánica del Consejo General del Poder Judicial en el proceso allí con-

12 Recuérdese si no las recomendaciones que efectuara el legislador en la STC 3/1983, de 25 de enero, en relación con el art. 170 de la Ley de Procedimiento Laboral, o en la STC 53/1985, de 11 de abril, resolutoria del recurso de inconstitucionalidad interpuesto contra la Ley de despenalización del aborto. 
templado para la propuesta de tales consejeros. No en balde, tras la aprobación de la Ley Orgánica del Poder Judicial asumirán aquellas asociaciones la actitud contraria a la fórmula consignada en ella que expresa su crítica constante hacia la misma, para la cual disponían entre otros argumentos con el que les proporcionaba el planteamiento jurisprudencial ahora objeto de análisis, por lo que tiene, según se adelantaba, de llamamiento a la independencia del Consejo.

Aunque se faltaría a la verdad de atribuirle ese origen único a los reproches que recibió la Ley Orgánica 6/1985, de 1 de julio, del Poder Judicial, por su modo de regular la propuesta de los miembros judiciales del Consejo, ignorando que, además de las referidas críticas, procedentes de las asociaciones judiciales, no faltaron las formuladas en el mismo sentido por la doctrina. Unas y otras terminarían por crear un estado de opinión según el cual los partidos políticos con representación en el Congreso y en el Senado se habrian limitado a operar, mientras estuvo vigente esa Ley, mediante el criterio de repartirse, proporcionalmente a su respectiva fuerza parlamentaria, esto es, por cuotas, el número total de puestos a cubrir en el Consejo General del Poder Judicial a la hora de proponer las Cámaras sus candidatos al mismo.

\subsection{El Pacto de Estado para la reforma de la Justicia}

Tal vez tuviera razón el Tribunal Constitucional y la Ley Orgánica del Consejo General del Poder Judicial propiciase que las Cortes subordinasen a un sistema de cuotas sus propuestas de candidaturas al Consejo. Quizá durante el tiempo indicado se condujeran los partidos políticos de acuerdo con ese criterio sin cuestionarlo. Puede incluso que esa actitud de los partidos haya concluido por afectar al prestigio del Consejo. Asi lo sostuvo el Ministro de Justicia en su comparecencia del 14 de febrero de 2001, ante la Comisión de Justicia e Interior del Congreso de los Diputados, quien decía hacerse eco de las críticas ciudadanas hacia la institución que, en su opinión, concluían por comunicarle una imagen clientelar de los partidos políticos. De modo que propugnaba para erradicarla un sistema que permitiese elegir a profesionales prestigiados en el mundo de la judicatura. En efecto, según el Ministro de Justicia, el Gobierno del Poder Judicial requería "cambios importantes y urgentes, muy especialmente en la forma de elección de los miembros del Consejo General del Poder Judiciali. Sustentaba esta conclusión con un argumento del que interesa dar cuenta en sus términos literales: 
«Escuchen señorías lo que dicen los ciudadanos de la calle: que con este sistema hay vocales del PP, vocales del PSOE o vocales de éste o de aquél, que las actuaciones de los vocales responden, en consecuencia, a los intereses de quienes les promovieron y que esta savia política irradia en toda la estructura jurisdiccional (...). Lo malo de este clima (...) es que tales juicios (...) están teniendo una incidencia determinante en los problemas de la justicia, como símbolo máximo del desprestigio de los ciudadanos $y$, lo que es probablemente peor, como elemento de deslegitimación de todo el poder del Estado (...). Resulta fácil imaginar docenas de sistemas de elección que, obviando semejante imagen de clientelismo, permitan elegir a personas del máximo prestigio en la profesión „13.

He aquí uno de los primeros pasos conducentes a la firma el 31 de mayo de 2001, del Pacto de Estado para la Reforma de la Justicia, entre el Gobierno de la Nación y los partidos Popular y Socialista, antecedente inmediato de la Proposición de Ley Orgánica sobre la composición del Consejo General del Poder Judicial, en cuya Exposición de Motivos se hacía constar que obedecía «al propósito de prestigiar el Consejo General del Poder Judicial».

A dicho objetivo, el de prestigiar la institución, apelarán alguna vez los participantes en los debates parlamentarios habidos sobre la Proposición de Ley, aunque nunca para cuestionar que el Consejo pudiera estar desprestigiado. Eso no lo descartaba ni siquiera una de las voces más críticas con tal Proposición de Ley, Lasagabaster Olozábal, según cabe deducir de su manifestación al respecto siguiente:

"(...) tampoco nos parece de recibo en esa exposición de motivos que se argumente constantemente que la reforma del sistema de nombramiento de los miembros del Consejo se haga para prestigiar la institución y garantizar su independencia. Contrario sensu parece que el anterior sistema o lo que hubiéramos hecho antes en esta Cámara no hubiera sido correcto, hubiera contaminado o hubiera desprestigiado la institución " ${ }^{14}$.

\subsection{La Ley Orgánica $2 / 2001$, de 28 de junio}

En cualquier caso, tales críticas a la Proposición de Ley apenas podian aspirar a obtener el reconocimiento de actitudes puramente

13 Cfr. D.S.C.D., Comisiones, núm. 142, de 14 de febrero de 2001, pág. 4278.

14 Cfr. D.S.C.D., Pleno y Diputación Permanente, núm. 89, de 12 de diciembre de 2001, pág. 4387. 
testimoniales, considerando el amplio respaldo que recibió aquélla. No en balde fue suscrita por los grupos Parlamentarios Popular en el Congreso, Socialista, Catalán (Convergencia i Unió), Vasco (EAJ-PNV) y de Coalición Canaria, lo que explica el resultado de la votación final sobre el conjunto de la propuesta, consistente en 248 votos a favor y 11 en contra. De ahí que tampoco tenga nada de particular la referencia consignada en la Exposición de Motivos de la Ley Orgánica 2/2001, de 28 de junio, a ese objetivo perseguido por la misma, pues, en efecto, según se hace constar allí acerca del Consejo General del Poder Judicial, dicha Ley Orgánica "se nutre del propósito compartido de prestigiar esta institución".

Quizá lo consiga, aunque si lo hace debe tenerse en cuenta que la única originalidad de la Ley Orgánica 2/2001, de 28 de junio, con respecto a las estipulaciones de la Ley Orgánica del Poder Judicial se reduce a dotar de transparencia todo el proceso selectivo de los 12 vocales judiciales del Consejo General del Poder Judicial, al contemplar su sucesora una fase inédita en dicho precedente legislativo, por la cual recuperan cierto protagonismo en dicho proceso las asociaciones profesionales de la judicatura, bien que compartido con el de los jueces y magistrados no afiliados a ninguna asociación, que cuenten con los debidos avales de sus compañeros, desde el momento en que basta con el respaldo de aquéllas o de éstos para presentar hasta un máximo de 36 candidatos para los doce puestos a cubrir. De entre los cuales le corresponde elegir, en primer lugar, seis al Congreso de los Diputados y hacer luego lo propio el Senado.

En lo demás puede decirse que la Ley Orgánica 2/2001 revalida la regulación de la Ley Orgánica del Poder Judicial. Difícilmente cabe sostener de la ley vigente, por tanto, que aporte ninguna novedad con que afrontar el riesgo denunciado por el Tribunal en su STC 108/1986, consistente en que las Cámaras atendiendo a la correlación de fuerzas en su seno distribuyan los puestos a cubrir en el Consejo entre los distintos partidos políticos, en proporción a su fuerza parlamentaria, de modo que no mantengan este asunto al margen de sus legitimas disputas. Conviene subrayarlo porque si, finalmente, la nueva Ley consigue evitar ese riesgo y aun sortear la mera probabilidad de su emergencia, habrá de concluirse que el problema, en realidad, no radicaba exclusivamente en un posible uso indebido por las Cortes de las facultades que en punto a la designación de los consejeros judiciales les confiere el art. 122.3 de la Constitución, cuanto, muy probablemente también, en la señalada restitución a las asociaciones de jueces y magistrados, cuando menos en parte, del protagonismo que, con arreglo a dispuesto en la Ley Orgánica del Consejo General del Poder Judi- 
cial, tenían en la designación de los vocales judiciales y habían perdido con la Ley Orgánica del Poder Judicial.

Dicho sea en otros términos, no es verosímil que el silencio del legislador de 2001 en cuanto a fórmulas orientadas a impedir el reparto por cuotas de los puestos a cubrir en el Consejo, pueda subsanarla su encomiable previsión de transparencia en el proceso destinado a la designación de sus miembros judiciales, si no es porque procedía del mundo judicial, y encontraron acogida en el ámbito de lo político, buena parte de las críticas vertidas hacia la institución, como respuesta a la pérdida, por las asociaciones judiciales, tras la Ley Orgánica del Poder Judicial, de su protagonismo en ese proceso. De tal modo que, una vez recuperado parte del mismo por éstas, pueda esperarse de sus buenos oficios y aun de la colaboración de los jueces y magistrados no afiliados a ellas, para que destruyan esa imagen clientelar de los partidos políticos, atribuida por el Ministro de Justicia a los miembros del Consejo, porque, en el caso de los consejeros judiciales, propongan como tales a esas "personas del máximo prestigio en la profesión" a las que, según se ha visto, se refería el Ministro de Justicia. En cuanto a los partidos políticos basta con que respeten el Pacto de Estado.

De suyo, el nuevo sistema de designación de los vocales judiciales no confiere al Consejo mayor ni menor grado de independencia de la que pudiera haberle proporcionado al órgano la Ley Orgánica del Poder Judicial. Pues, seguramente que a su independencia se refería el Tribunal Constitucional en su STC 108/1986, bien que no a la exigida por la Constitución para los jueces y magistrados, sino a la necesaria tan sólo para su desvinculación del Gobierno. No se olvide que el Consejo sustituye al Ministro de Justicia en las tareas atinentes al gobierno del Poder Judicial que la Constitución le asigna. A cuyo propósito conviene insistir en que, a fin de atribuirle tal grado de independencia, confía la Constitución en su configuración plural, resultante de combinar, como se decía en la STC 108/1986, la presencia en dicho órgano de las principales actitudes y corrientes de opinión existentes en el conjunto de jueces y magistrados con las de otros juristas que, a juicio de ambas Cámaras, puedan expresar la proyección en el mundo del Derecho de las distintas corrientes de pensamiento existentes en la sociedad ${ }^{15}$. Sin que medie ninguna duda respecto al hecho de favorecer la obtención del objetivo indicado, la exigencia de mayorías cualificadas para la propuesta de una y otra clase de consejeros.

15 Cfr. CTC 108/1986, de 29 de julio, F.J. 13. 


\section{SOBRE LAS CRÍTICAS COYUNTURALESY LAS DE CARÁCTER PERIÓDICO AL CONSEJO}

El tipo de crítica hasta aquí descrito no agota el catálogo de las que ha recibido el Consejo a lo largo de estos años. De muy distinta naturaleza a las referidas han sido las más frecuentes y, por tanto, más numerosas que ha cosechado el órgano en el ejercicio de las funciones que le ha encomendado y le encomienda la Ley. Tantas han sido las de esta clase que, en la imposibilidad de informar a su respecto con un mínimo de rigor, se renuncia a dicha tarea para, en su lugar, informar sobre la crítica de esta índole más significada de todas. De ella da cumplida cuenta Sainz de Robles cuando refiere las diferencias que se produjeron en 1982 entre el Gobierno y el Consejo General del Poder Judicial por entender aquél que éste había invadido las competencias ejercidas hasta entonces por el Ministro de Justicia en relación con la Escuela Judicial, y a su información conviene remitirse ${ }^{16}$.

Aunque en honor a la verdad conviene aclarar que sólo una mínima parte de las críticas vertidas sobre el Consejo de forma episódica o incidental, por causas concretas y determinadas de su proceder, tienen, como la recién descrita, una dimensión institucional. Las más suelen ser de otra índole, no obstante situarse también en su origen una actuación específica de aquél. El sólo hecho de ser un órgano colegiado y plural en cuanto a sensibilidades, actitudes y opiniones, hace que, de ordinario, sea la mayoría y no la unanimidad la fórmula sustentadora de sus acuerdos. Súmese a eso la facultad que alcanza a los consejeros de hacer constar en un voto particular sus discrepancias con la decisión mayoritaria y obsérvese la magnífica oportunidad que, como consecuencia de todo ello, se les presenta a los partidos de situar al Consejo en el centro de sus miras y de convertir en objeto destacado del debate político esas decisiones del órgano cuestionadas por sus propios miembros.

Quizá no sea ocioso añadir que la contingencia descrita no es puramente teórica. Hágase memoria si no de las ocasiones en que durante todos estos años ha podido asistirse al fenómeno por el cual

16 Bien que eso no es obstáculo para hacer constar aqui que, según añade al respecto el citado autor, "este conflicto no llegó a formalizarse ante el Tribunal Constitucional, por el fin de la legislatura; el Gobierno Socialista renunció a mantenerlo como gesto amistoso y pienso yo, por coherencia con aquel proyecto alternativo que claudicó junto al de UCD". Cfr. Poder Judicial y Consejo General del Poder Judicial, cit., pág. 398. 
la oposición, haciendo suya alguna opinión disidente de las enunciadas en los votos particulares a cualquier decisión del Consejo, ha reprobado la misma no sin calificarla de beneficiosa para los intereses del Gobierno.

Ahora bien, con estas críticas proferidas hacia el Consejo de manera episódica y coyuntural, no concluye, sin embargo, la lista de reproches en relación con los cuales éste deviene protagonista. Pues, junto a los mencionados hasta ahora deben tenerse presentes los inspirados no tanto en el proceder del órgano cuanto en la circunstancia de su renovación. A ellos no han sido ajenos en absoluto los partidos políticos sino que, antes bien, sin su participación activa no se habría convertido al Consejo en el sujeto pasivo de tales críticas con el efecto subsiguiente de erosionarlo. Como, por cierto, asi lo reconocía uno de los participantes en los debates parlamentarios previos a la aprobación de la Ley Orgánica 2/2001, de 28 de junio, López Aguilar, para quien, según sus propias palabras:

"Ha sido imposible que en la historia constitucional del órgano, en veinte años de funcionamiento del Consejo, una sóla renovación de ese mandato quinquenal que la Constitución establece haya sido pacífica, se haya producido en tiempo y forma coincidiendo con la caducidad del mandato. Por el contrario tenemos perfecta memoria de episodios de desencuentro, de litigio, de desgaste, de erosión del órgano y de todos sus integrantes que han llegado a caer en la fase final en una suerte de abulia depresiva que les invitaba a la dimisión para incorporarse a sus puestos de origen o al abandono del ejercicio de sus funciones, a pesar de que en la práctica se les estaba prolongando el mandato ${ }^{17}$.

Hasta aquí las críticas en que, por un motivo u otro se ha visto envuelto el Consejo. Dígase si podría confiarse sólo en las virtudes de la Ley Orgánica $2 / 2001$, de 28 de junio, para reducir su número o ponerles término, o si tales finalidades se estiman, en cambio, inalcanzables de no mediar además el concurso de los partidos para excluir al Consejo de sus disputas políticas ordinarias.

17 Cfr. D.S.C.D., Pleno y Diputación Permanente, núm. 89, de 12 de junio de 2001, pág. 4379. 